\title{
New Enhanced Acoustic Damping Composite Material for the Aeronautics Industry
}

\section{EMUS 2019}

\section{PASTORINO* ${ }^{*}$, J. DI LORENZO ${ }^{\dagger}$, B. LÓPEZ-ROMANO ${ }^{*}$, P. HADLEY ${ }^{\dagger}$ AND T. BLANCO $^{\S}$}

\author{
* FIDAMC, Foundation for the Research, Development and Application of Composite Materials \\ Avda. Rita Levi Montalcini 29, 28906 Getafe, Madrid, Spain \\ ${ }^{\dagger}$ Hexcel Composites, Ickleton Road, Duxford, Cambridge, CB22 4QB United Kingdom \\ ${ }^{\S}$ Airbus Operations, S.L., Paseo de John Lennon, S/N, 28906 Getafe
}

Key words: Aerospace, acoustic performance, composite material

\begin{abstract}
The present article investigates an innovative structural composite material concept with the additional functionality of acoustic damping. It is achieved by introducing an embedded elastomeric layer within the composite laminate, which constitutes a constrained layer damping (CLD) system. The main objective is to increase the acoustic performance of the baseline material, while its mechanical properties are maintained. In addition, material processability and inspectability have been considered as important drivers for the technology development. In order to identify the most promising candidate, a set of alternatives has been explored and analysed, giving rise to a compromise solution between the enhanced acoustic performance and the structural properties of the baseline material.
\end{abstract}

\section{INTRODUCTION}

The aim of the present study is to investigate a structural composite material concept with the additional functionality of acoustic damping. To this end, a standard modulus Carbon Fiber Reinforced Plastic (CFRP) prepreg is used as the baseline material. The damping performance of this substrate prepreg is enhanced by the addition of an elastomeric layer (EL), which becomes embedded in the composite structure when formed. The elastomeric layer, which is designed to co-cure with the thermoset prepreg, acts as part of a constrained layer damping (CLD) system. This confers vibration damping performance on the cured laminate.

The target application of the present study is the fuselage skin. The existing solution requires the manual addition of heavyweight, bespoke damping elements that are applied following part production and assembly. Such an approach adds inventory, time, weight and, ultimately, cost. The main drivers for the exploration of this technology are the potential for weight saving, maintaining or increasing production rate and the cost savings associated with these benefits. These are all key targets in the commercial aerospace sector. Weight savings and cost reductions are delivered in part by the embedded nature of the damping solution. The modified prepreg can be processed using established manufacturing techniques such as 
Automated Fibre Placement (AFP) or Automated Tape Laying (ATL). This allows for high production rates.

Acoustic performance of a range of elastomers and composite structures was assessed within the range $-55^{\circ} \mathrm{C}$ to $70^{\circ} \mathrm{C}$ using a modified Oberst beam test. Modal analysis was performed on the resonant peaks of test specimens, and the loss factor for the second and third resonant modes were determined using the half-power bandwidth method.

With regard to structural performance, it would be desirable to maintain substantially the same level of performance as the reference CFRP. The introduction of a rubbery layer within a laminate is likely to have a detrimental effect on its mechanical performance. However, it is recognised that a decrease in mechanical performance may be tolerable if a substantial weight saving or cost decrease can be achieved. Additional measures may then be taken to recover performance. A mechanical test campaign has been performed in order to quantify the structural behaviour of the multifunctional solution proposed.

It has been demonstrated that damping effectiveness is related to the relative amount of shear stress in the $\mathrm{x}-\mathrm{y}$ plane, the best damping performance being associated with the positioning of the damping element at the location of maximum shear during bending. Placing the damping element centrally within the simple test specimen of this study was found optimal from a damping perspective, but then delivered the poorest mechanical performance. Strategies to mitigate this contradiction were explored.
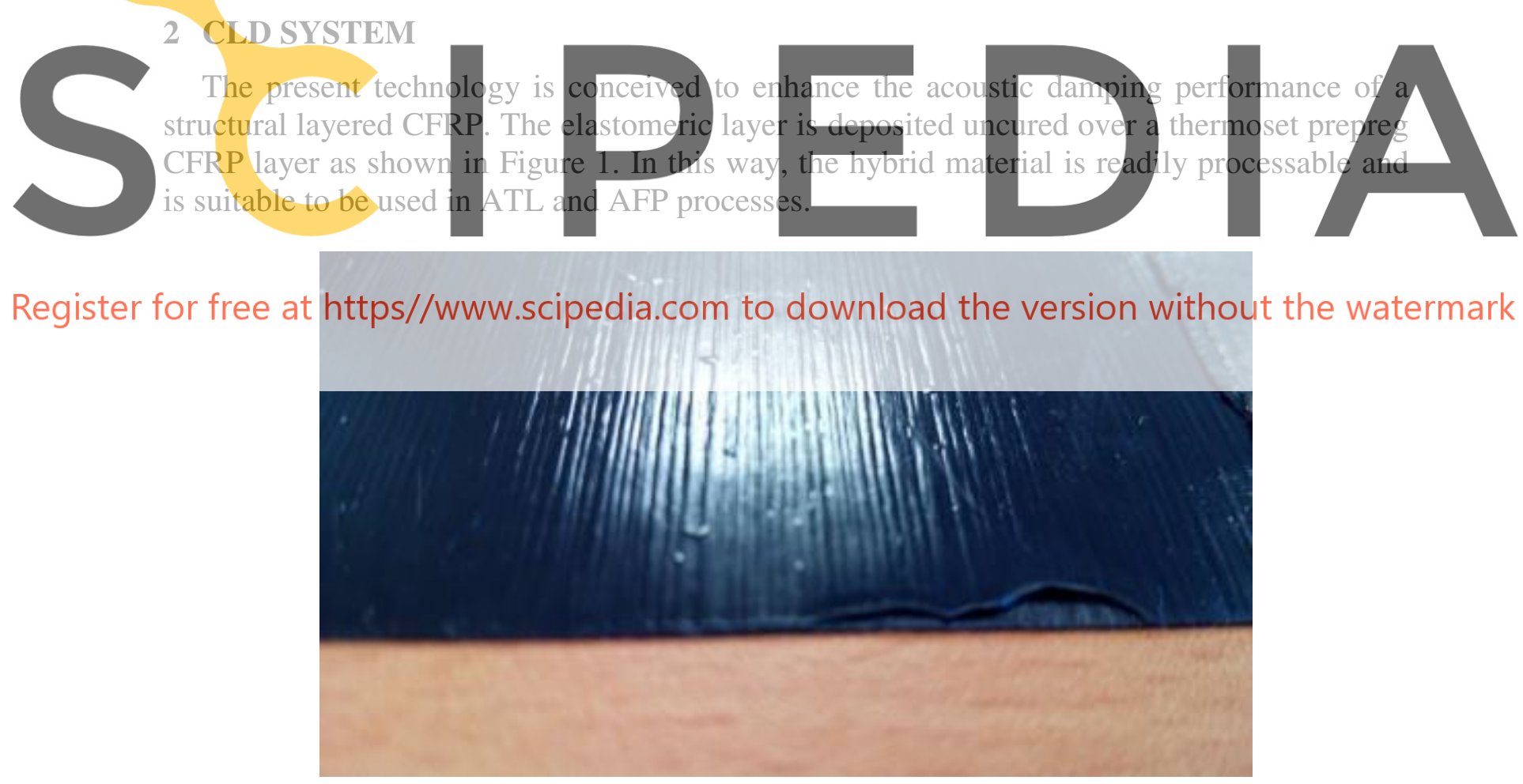

Figure 1: Detail of the elastomeric layer, deposited over a CFRP layer.

Figure 2 shows a laminate cross section, where the EL is perfectly visible at the centre of a composite panel. 


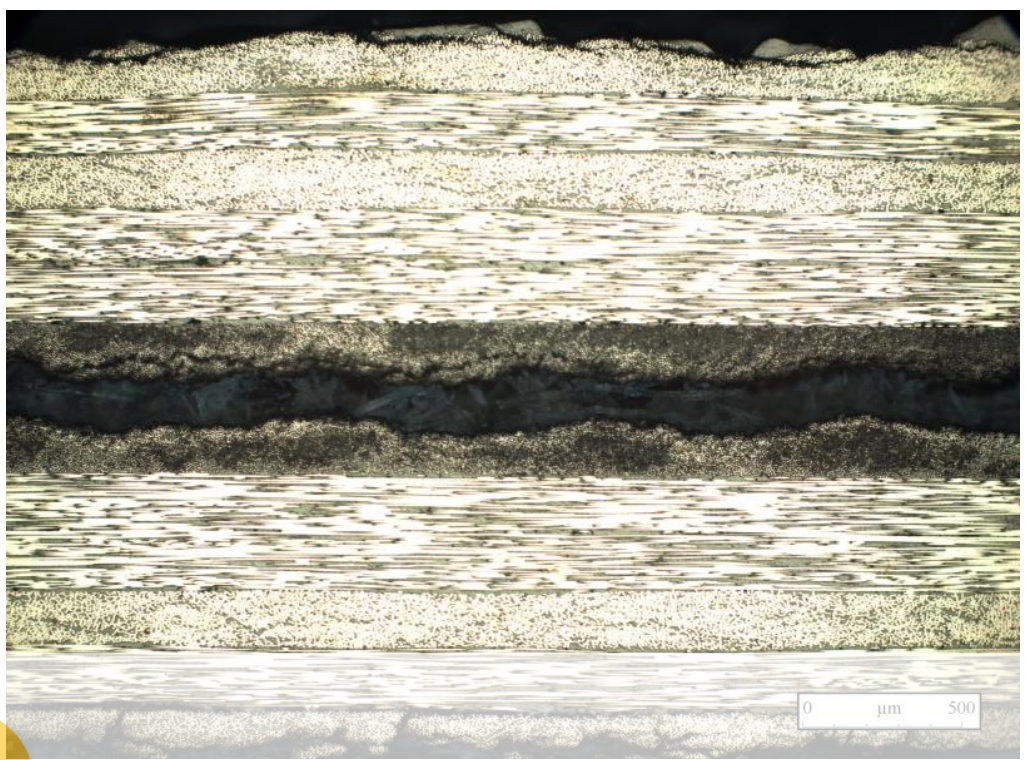

Figure 2: Microscopy of the transverse section of a coupon with a centred elastomeric layer.

\subsection{Elastomer formulation}

A polyisoprene based rubber was selected following the preliminary screening of three

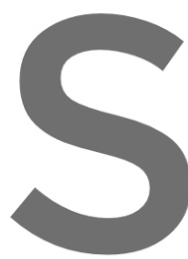
engineered rubber coin monomer rubber conp temperature range o compound performed the best $800 \mathrm{~Hz}$ to $1100 \mathrm{~Hz}$.
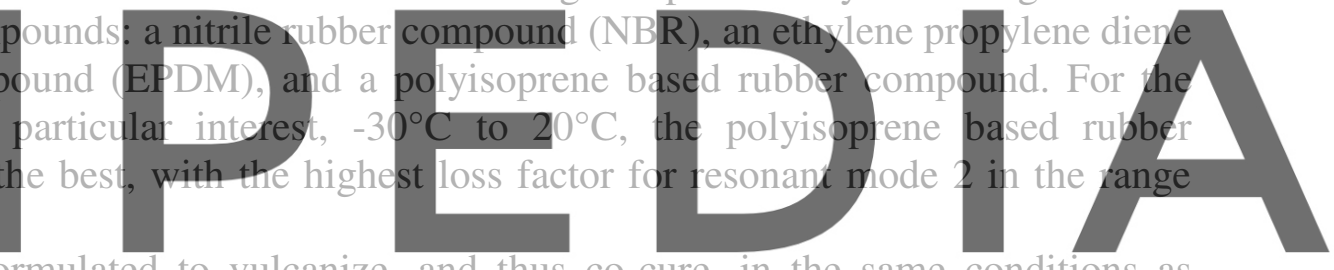

The elastomer is formulated to vulcanize, and thus co-cure, in the same conditions as

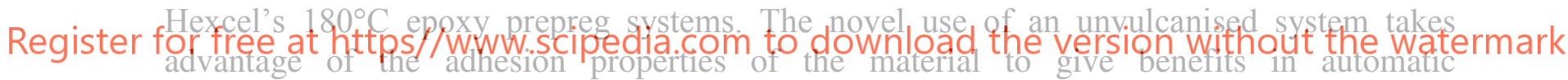
processability.

\subsection{Laminate architecture}

One of the most critical decisions of the present research project has been to propose a laminate architecture that fulfils both acoustic and mechanical requirements. To this end, a $[+45 / 0 /-45 / 0 / 0 / 90]$ s laminate is used as the reference lay-up. On this basis, one or more elastomeric layers have to be embedded within the reference lay-up in order to maximise the acoustic performance with the minimum effect on the mechanical properties.

In a first phase, the main driver for the selection of the laminate architecture was the fulfilment of the acoustic performance at minimal additional weight. Subsequently, several alternatives have been tested in order to keep the mechanical performance above an acceptable level. The definition of each architecture contemplates the following modifiable parameters:

- $\quad$ Position of the EL. The EL is placed at a certain distance from the laminate midplane.

- $\quad$ Thickness of the EL. Normally, an elastomeric layer thickness increment implies 
better acoustic performance, compared with thinner layer in same position, penalizing weight.

- Number of EL. The usual configuration involves just one elastomeric layer. However, a trial has been carried out considering two symmetric off-centred films inserted within the laminate.

\section{TEST PLAN}

After a preliminary phase in which a great number of alternatives were proposed and investigated, a concise test plan is conceived, in which the most promising laminate architectures are considered. The test plan is conducted in order to achieve the best combination of mechanical and acoustic performances. Although other targets are sought and analysed, as processability and non-destructive inspectability, the preferred laminate architecture is selected just in view of the mechanical and acoustic results. The alternatives analysed in the test plan are shown in Table 1.

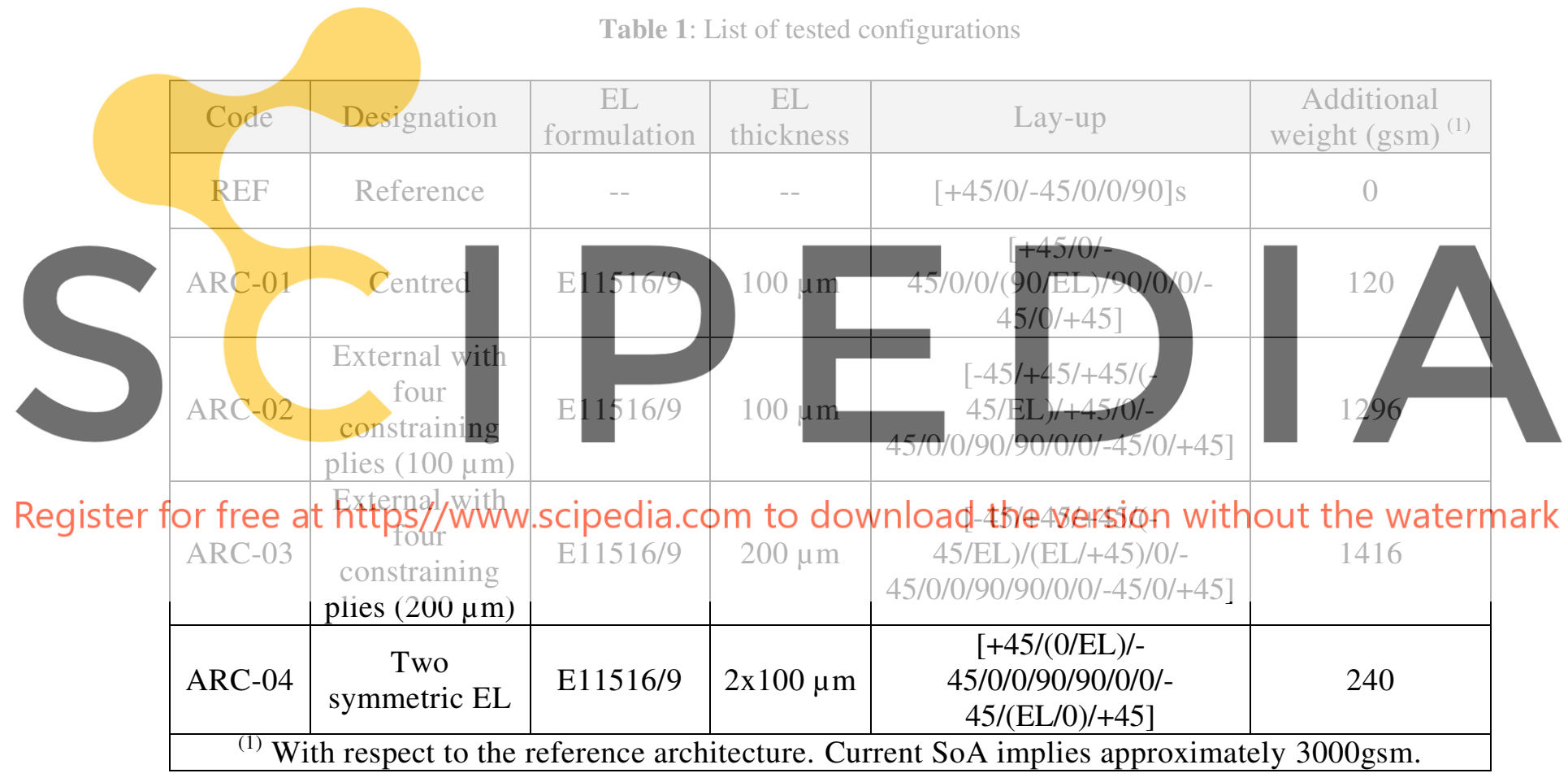

It should be noted that the architectures that require the use of constraining plies (ARC-02 and ARC-03) are heavier (with respect to the reference laminate). However, these architectures are optimal for the structural performance, since the EL is moved outside from the coupon centre.

\subsection{Acoustic performance}

As a target for the investigation a temperature range of interest of $-30^{\circ} \mathrm{C}$ to $20^{\circ} \mathrm{C}$, and a loss factor of $\geq 0.05$ for the second and third resonant modes was defined in agreement with the Airbus S.L. The targets reflect the early technology stage of the concept, and do not 
constitute a full specification for the damping requirements of an aircraft.

Acoustic performance is assessed using a modified Oberst test method. The method is based upon the testing standard ISO 16940 [1], with two modifications: i) the representative layup is used instead of a $4 \mathrm{~mm}$ thick beam, ii) the test is performed at multiple temperature ranges in $5^{\circ} \mathrm{C} \pm 1^{\circ} \mathrm{C}$ intervals. To accomplish this, a $300 \mathrm{~mm}$ steel stinger rod at $5 \mathrm{~mm}$ diameter is used to hold the sample in an environment chamber for testing. The stinger rod has an undesirable contribution effect to the results at $600 \mathrm{~Hz}, 700 \mathrm{~Hz}$ and $950 \mathrm{~Hz}$, but is sufficient for the benchmarking and comparison purposes of this study. The results of acoustic testing of resonant mode 2 are shown in Figures 3 and 4.

From the results, two important design variables for a successful CLD approach can be extracted; the thickness of elastomeric layer, and the proximity of the EL to the central axis of the material.

In the interest of minimizing the additional weight of any new structural material, it is clear from the results that for a given material the proximity to the central axis is important for achieving the maximum damping potential of this technology. ARC-01 has the highest peak loss factor performance of all the samples tested with the smallest amount of additional weight. This is because the elastomeric layer is placed in the location of the laminate that experiences the highest shear stress during bending, maximizing the potential for energy dissipation through shear deformation. Whilst the correlation between shear stress and damping performance was not explicitly investigated as part of this study, this is a reasonable

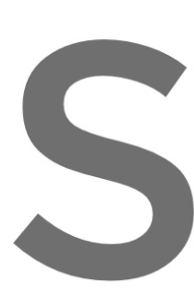
conclusion when one shear deformation.

\section{Register for free at https//www.scipedia.com to download the version without the watermark}

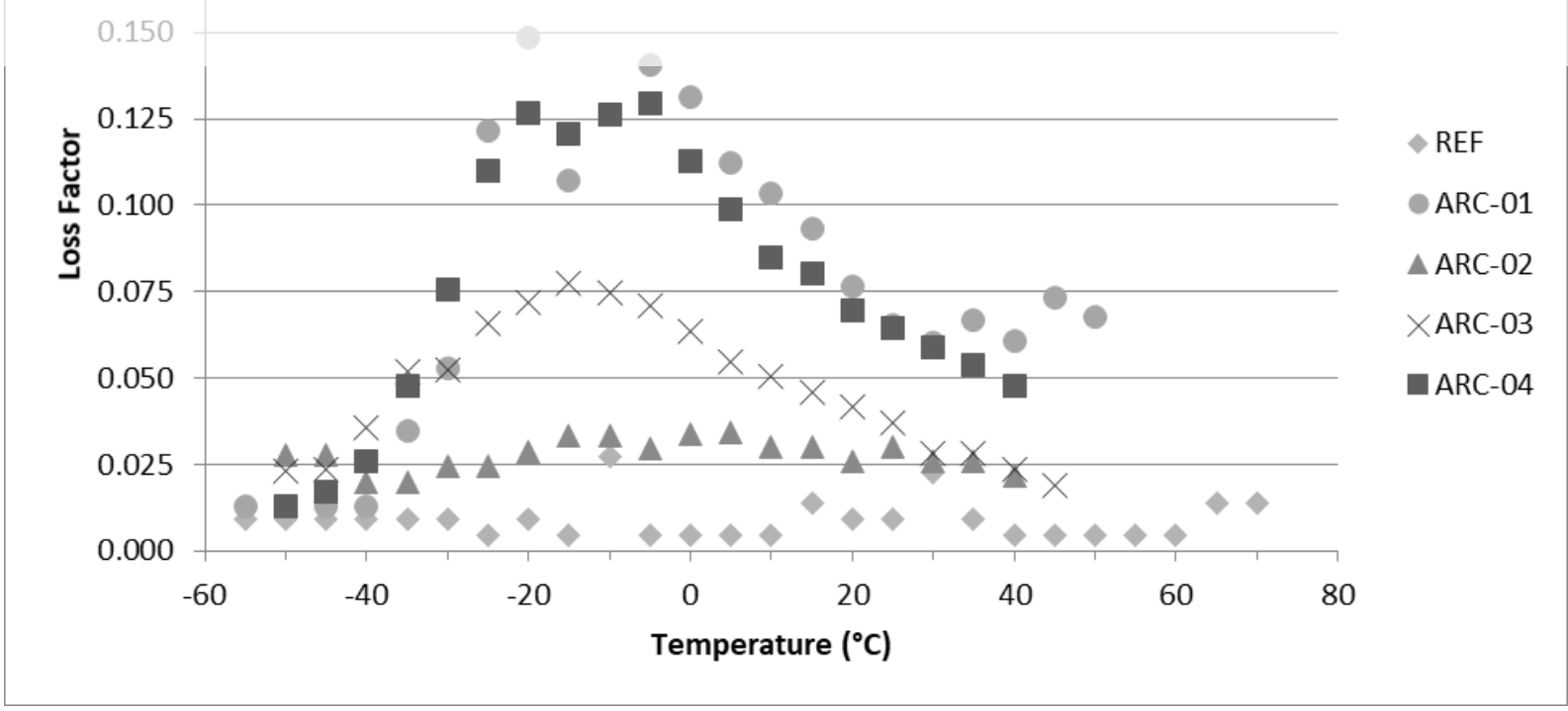

Figure 3: Loss factor vs temperature for the second resonant mode of tested samples. 

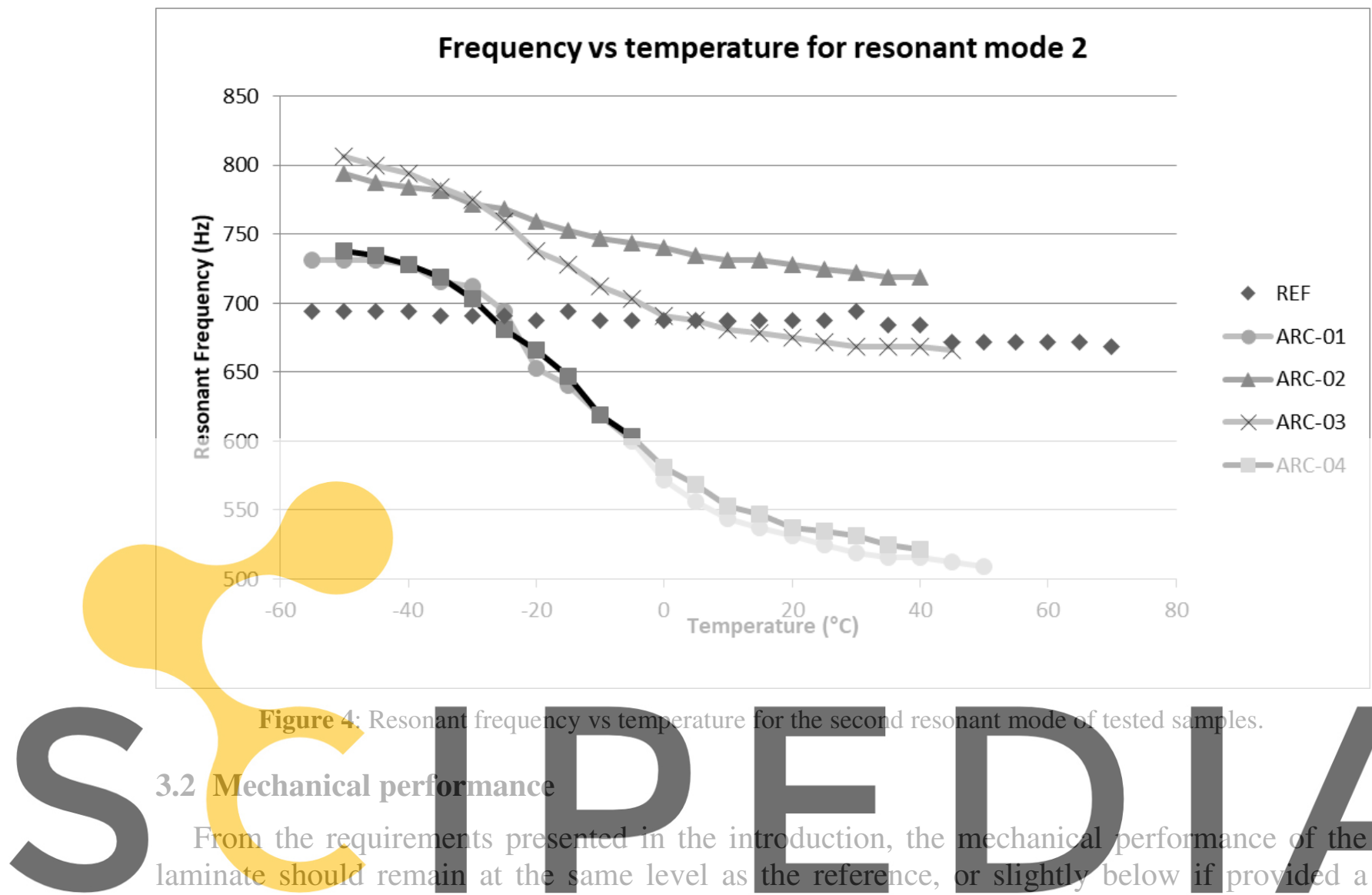

Figure 4: Resonant frequency vs temperature for the second resonant mode of tested samples.
3.2 Mechanical performance
From the requirenents presented in the introduction, the mechanical performance laminate should remain at the s

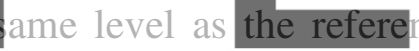

or slightly below if

significant improvement on the component weight with respect to the current state of the art

Register for r $^{9}$ Preegsm httos//www.scipedia.com to download the version without the watermark Mechanically, the elastomeric layer acts as a physical division or barrier inside the laminate. The shear loading capacity of the elastomer is very limited due to its low stiffness. In fact, this is why the elastomeric layer has an outstanding acoustic performance. Clearly, this effect is counterproductive from the mechanical point of view, and hence it is desirable to have the EL as far away from the laminate centre as possible.

In order to test the influence of the elastomeric layer in the laminate a mechanical test campaign is conducted. Although a complete characterization has been performed, it was the 3-point bending test (acc. to EN2562 type A [2]) that leads to the most valuable results. The results are compared with respect to the reference in Table 2.

Table 2: Mechanical performance of the laminate architectures tested, with respect to the reference, based on 3 point bending test

\begin{tabular}{|c|c|c|}
\hline Code & 3-point bending test strength $(\%)^{(1)}$ & Failure mode \\
\hline REF & 100 & Bending \\
\hline ARC-01 & $50.5^{(2)}$ & Out-of-plane shear \\
\hline
\end{tabular}




\begin{tabular}{|c|c|c|}
\hline ARC-02 & 102 & Out-of-plane shear \\
\hline ARC-03 & 117.8 & Out-of-plane shear \\
\hline ARC-04 & 47.3 & Out-of-plane shear \\
\hline \multicolumn{3}{|c|}{$\begin{array}{c}\text { (1) With respect to the reference coupons. } \\
\text { (2) The test have been carried out with Uni-Directional coupons (UD), the } \\
\text { results are compared with a UD CFRP set of coupons. }\end{array}$} \\
\hline \multicolumn{2}{|c|}{}
\end{tabular}

Here, architectures ARC-02 \& ARC-03 show an improved mechanical strength with respect to the reference, which is expected since it is the same laminate with an extra EL and 4 additional plies. The coupons with $200 \mu \mathrm{m}$ of EL thickness show higher strength than the coupons with $100 \mu \mathrm{m}$ EL.

Finally, it should be mentioned that the failure mode changes with the inclusion of the elastomeric layer. The coupons with elastomeric layers normally fail by a combination of outof-plane shear and bending, while the failure of the reference coupons is caused by pure bending. Figure 55 shows the differences on the failure of both configurations, the out-ofplane shear failure affects uniquely to the interface of the elastomeric layer with the adjacent CFRP layers, causing a slippage phenomenon during the test. This phenomenon causes the early failure of specimens with architectures ARC-01 and ARC-04.
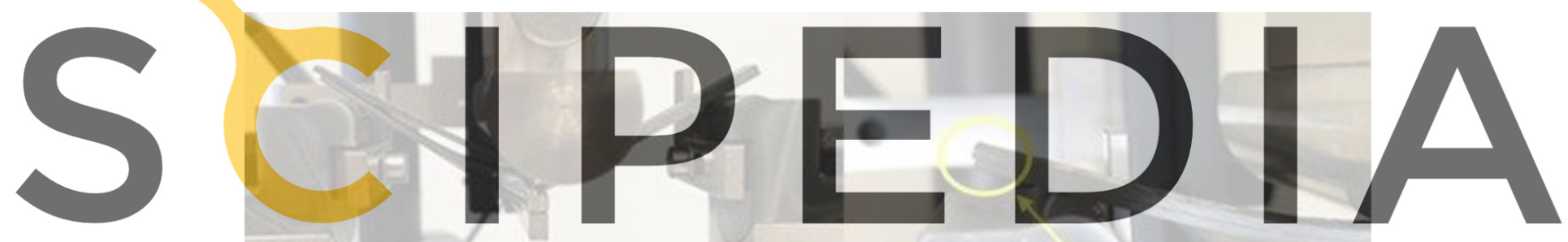

Register for free at https//www.scipedia.com to download the version without the watermark

Figure 5: Bending failure mode of a reference coupon (left) and slippage phenomenon on a coupon with elastomeric layer (right).

\subsection{Overall performance}

The following conclusions are extracted by comparing the hybrid laminates with respect to the reference:

- The elastomer placed centrally gives rise to the best acoustic performance at the expense of reducing substantially the mechanical performance. The best solution from the structural point of view is to position the elastomeric layer near one of the external faces, under some constraining plies.

- Using a thicker elastomeric layer is beneficial from the acoustic point of view, and has been reported not to affect the mechanical performance negatively. Elastomeric layers up to $200 \mu \mathrm{m}$ have been analysed. 
- The use of two symmetrical elastomeric layers enhances the acoustic performance, but the mechanical performance is excessively poor.

Thus, the best combination of mechanical and acoustic performances is reached by using the configuration designated as ARC-03. A $200 \mu \mathrm{m}$ EL is placed off-centre under 4 constraining plies.

\section{OTHER ASPECTS OF PERFORMANCE}

\subsection{Processability}

The material has been slit to $300 \mathrm{~mm}, 150 \mathrm{~mm}$ and $75 \mathrm{~mm}$ for Automated Tape Laying (ATL) production, using a release liner to avoid the self-bond of the material. It is always laid-up with the EL positioned upwards, and the CFRP ply downwards.

ATL manufacturing trials demonstrated that the adhesion of the EL to the next ply of CFRP is high enough to facilitate standard lay-up processes. In addition, the automated trimming systems have demonstrated an excellent performance with the hybrid material.
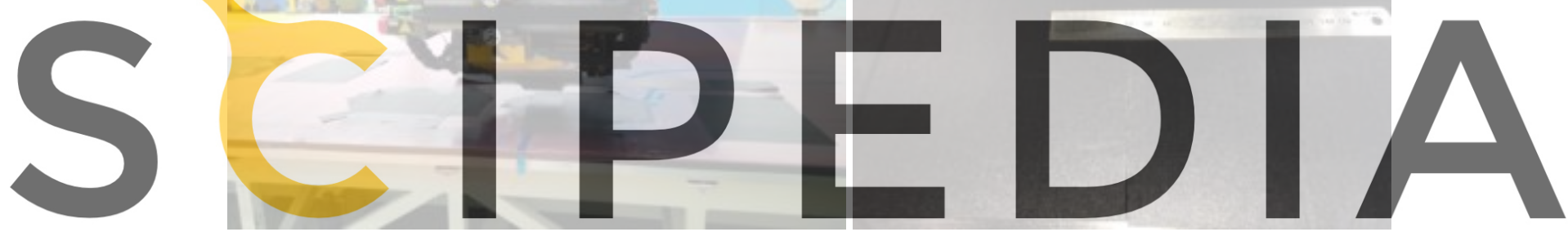

Figure 6: Automated deposition of the hybrid material by using ATI.

Register for free at https//www.scipedia.com to download the version without the watermark

In addition to ATL material, it has been produced slit-tape material for Automated Fibre Placement (AFP) lay-up processes. However, no manufacturing trials have been performed for the time being.

\subsection{Non-destructive testing (NDT)}

In CFRP laminated composites, it is essential to be able to detect internal defects in the laminate, since hidden damage could lead to an unexpected failure of the structure. Usually, the detection and characterisation of defects is performed by using non-invasive techniques, such as the ultrasonic inspection (US).

Some interesting conclusions are drawn from the analysis of inspected CLD specimens. The elastomeric layer embedded into the laminate behaves as a damper that attenuates the ultrasonic wave. In fact, an attenuation of approximately $6 \mathrm{~dB}$ is found on the CLD specimens with respect to the reference (just CFRP) specimens. This attenuation is not worrisome, since it is uniform and well distributed over the surface.

In addition, a 4-step flat panel with thicknesses of 2.308, 3.412, 4.516 and $5.620 \mathrm{~mm}$ respectively and Armalon inserts of $4 \times 4 \mathrm{~mm}$ and $6 \times 6 \mathrm{~mm}$ as defects has been manufactured 
and US inspected. The conclusions obtained are that the defects are detectable by manual and automatic inspection. However, the depth of the defects is hardly identifiable due to the elastomer insertion into the laminate, see Figure 7.

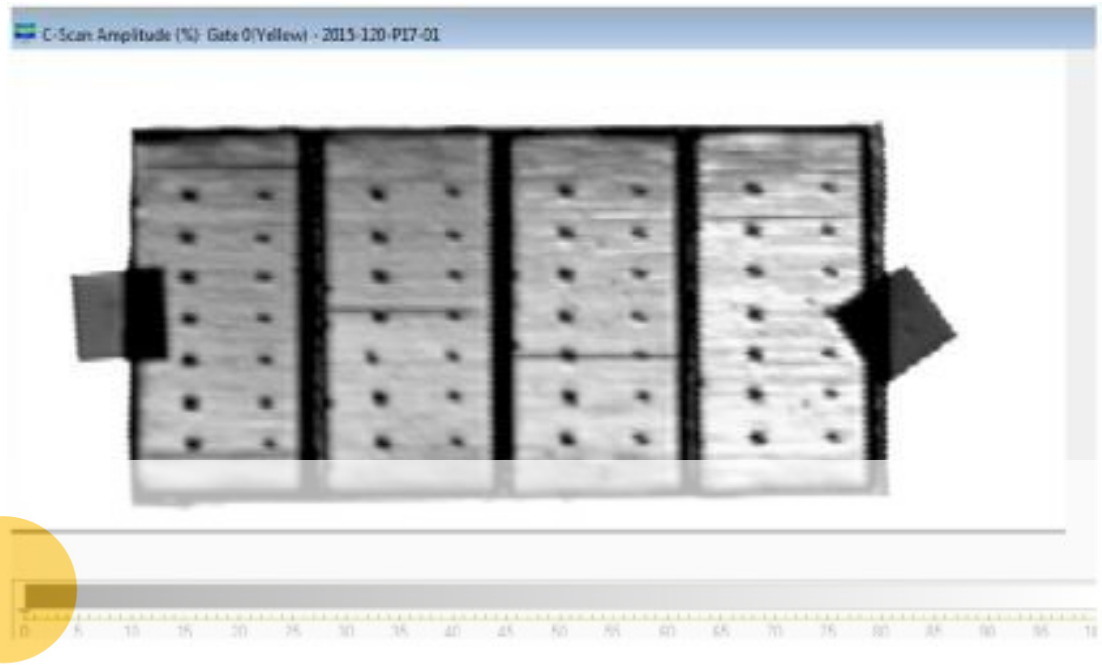

Figure 7: Amplitude C-Scan for a 4-step flat panel manufactured. Intentionally introduced defects are visible as dark spots.
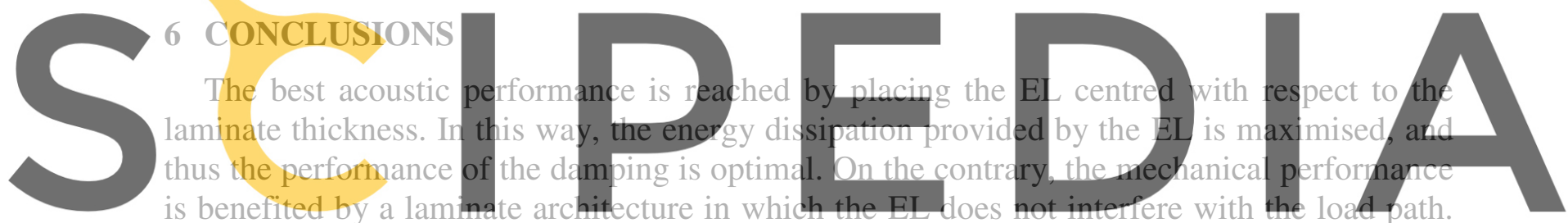

This is achieved by positioning the EL outside of the load path of the structural laminate, and

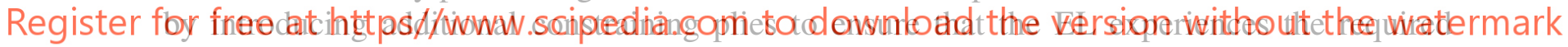

shear deformation during bending. In this way, the CFRP plies placed beyond the "structural part" of the laminate are important design variables, along with EL thickness and the type of EL, for achieving any specified level of acoustic performance.

A compromise solution for acoustic and mechanical performance has been found, which consists of placing an elastomeric layer of $200 \mu \mathrm{m}$ thick externally under four constraining plies. The multifunctional material developed has proven itself interesting for the aerospace industry in terms of acoustic and mechanical performance. Additionally, the automated processability of the CLD system has been demonstrated, as well as its inspectability by means of NDT.

Finally, the drivers initially suggested for this development are completely fulfilled. In the first place, a potential weight saving is foreseen with the chosen architecture with respect to the current SoA. Secondly, the production rate could be significantly improved, since the investigated CLD system is suitable for automated lay-up processes, while the current reference requires a manual installation process. Improvements in production rate yield a significant reduction in the cost of the finished component.

The present study has been carried out under NEODAMP (New Enhanced acOustic DAMPing composite material) project. The NEODAMP project has been funded by the 
European Union's Horizon 2020 and by Clean Sky Joint Technology Initiative under grant agreement number GA: 686374.

\section{REFERENCES}

[1] ISO 16940. Glass in building glazing and airborne sound insulation. Measurement of the mechanical impedance of laminated glass: 2008. Standard commonly known as Centre Impedance Method or Modified Oberst Test.

[2] EN2562. Aerospace series. Carbon fibre reinforced plastics. Unidirectional laminates flexural test parallel to the fibre direction.
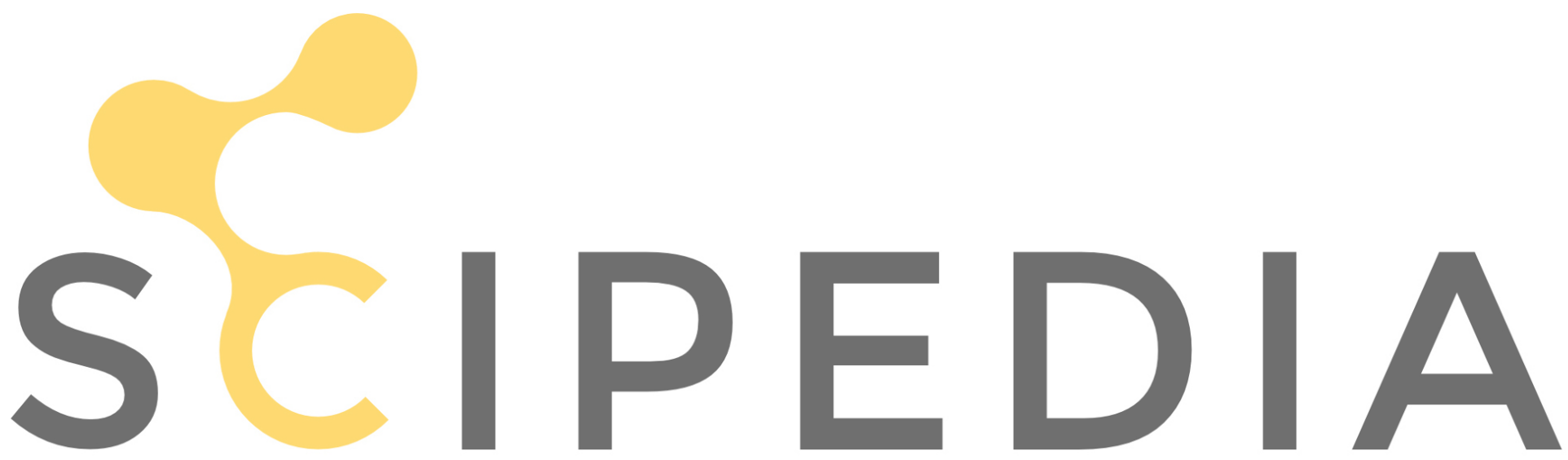

Register for free at https//www.scipedia.com to download the version without the watermark 